\title{
Pemetrexed plus cisplatin/carboplatin in previously treated locally advanced or metastatic non-small cell lung cancer patients
}

\author{
Guan-Zhong Zhang, Shun-Chang Jiao* and Zhao-Ting Meng
}

\begin{abstract}
Background: The objective of this study was to evaluate the efficacy and safety of pemetrexed plus cisplatin/ carboplatin in locally advanced or metastatic non-small cell lung cancer (NSCLC) patients previously treated with platinum-based chemotherapy.

Methods: Fifty-three locally advanced or metastatic non-small cell lung cancer patients previously treated with platinum-based chemotherapy received pemetrexed $500 \mathrm{mg} / \mathrm{m}^{2}$ plus cisplatin $75 \mathrm{mg} / \mathrm{m}^{2}$ or carboplatin area under the curve (AUC) 5 every 21 days, with dexamethasone, folic acid and vitamin B12 being administered.

Results: Median age was 52 years. Eastern Cooperative Oncology Group (ECOG) performance status was 0-2. Thirtyeight patients had stage IV tumors. Thirty-seven patients had adenocarcinoma (including 6 alveolar carcinoma patients), and fourteen patients had squamous cell carcinoma. Thirty-four patients were treated in second line, 15 in third line, and 4 in fourth line. Seven patients (13.2\%) showed partial response; Thirty-six (67.9\%) had stable disease. The median progression free survival time was 6.0 months and the median overall survival time was 10.0 months. The 1year survival rate was $40.9 \%$. Five (9.4\%) and four (7.5\%) patients experienced grade 3 or 4 leukopenia and thrombocytopenia, respectively. Nonhematological toxicities included grade 3 nausea/vomiting in 1 patient (1.9\%), grade 3 rash in 1 patient, grade 4 diarrhea in 1 patient (1.9\%) and grade 4 creatinine increase in 1 patient (1.9\%).
\end{abstract}

Conclusion: Locally advanced or metastatic NSCLC patients previously treated with platinum-based chemotherapy could benefit from pemetrexed plus cisplatin/carboplatin chemotherapy with tolerable adverse events.

\section{Background}

Lung cancer is the most common cause of death from cancer among men and women in the world [1]. Nonsmall cell lung cancer (NSCLC) accounts for $80 \%$ of all cases of lung cancer, with $65 \%$ to $75 \%$ of them having locally advanced or metastatic disease [2,3].

Combination chemotherapy is regarded as the standard treatment of unresectable locally advanced or metastatic NSCLC. Platinum-based chemotherapy with a third-generation agent (gemcitabine, paclitaxel, docetaxel, or vinorelbine) has significantly improved median survival and quality of life in those patients [4]. Despite these advances, therapeutic results are still far from optimal.

\footnotetext{
*Correspondence: jiaosc2009@126.com

1 Department of Oncology Medicine, Chinese PLA General Hospital, 28\# Fuxing Road, Haidian District, Beijing, 100853, PR China

Full list of author information is available at the end of the article
}

Most patients receiving front line chemotherapy experience disease progression [5].

The current options for the second line treatment of locally advanced or metastatic NSCLC are docetaxel, pemetrexed and erlotinib. Docetaxel is the first drug approved for second line treatment [5]. Pemetrexed was approved in second line therapy in NSCLC on the basis of a phase III trial comparing pemetrexed versus docetaxel. In this trial, pemetrexed showed a similar clinical activity and a lower rate of myelosuppression compared to docetaxel [6-8]. Erlotinib, an epidermal growth factor receptor inhibitor, was approved in the U.S. and Europe for NSCLC second line treatment after a study showed its superiority over best supportive care (BSC) in recurrent NSCLC patients [9].

Pemetrexed is a multitargeted antifolate cytotoxic chemotherapy agent, which inhibits at least three target 
enzymes in the folate pathway (thymidylate synthase, dihydrofolate reductase, and glycinamide ribonucleotide formyl transferase). As a consequence, pemetrexed interferes with the synthesis of both pyrimidine and purine, thereby effectively inhibiting both DNA and RNA synthesis[10] Several reports have documented the efficacy of a platinum based combination therapy with pemetrexed is similar to other standard platinum doublets [11-13]. Pemetrexed in combination with cisplatin was recently granted as first-line treatment of advanced nonsquamous histology NSCLC patients [14-17].

In December 2005, pemetrexed was approved in China. Platinum-based chemotherapy played an important role in the treatment of NSCLC $[18,19]$. Clinical trials have proved the safety of pemetrexed in combination with platinum [20-22]. We designed the study to gain clinical experience with pemetrexed plus platinum in previously treated patients with locally advanced or metastatic NSCLC. The objective of this study was to evaluate the efficacy as well as safety of pemetrexed plus platinum in previously treated patients with locally advanced or metastatic NSCLC.

\section{Methods}

\section{Patients}

All consecutive patients with histologically confirmed previously treated locally advanced or metastatic NSCLC were enrolled in this study. All patients had experienced platinum-based chemotherapy, and none of them had received pemetrexed as part of the treatment. For all patients, prior chemotherapy had been completed at least 21 days prior to the start of the study and the patients have recovered from any acute toxic effect of previous therapy. Further inclusion criteria were: age $<70$ years and life expectancy $>8$ weeks, Eastern Cooperative Oncology Group (ECOG) performance status was 0-2, and adequate haematologic (absolute neutrophil $\geq 1.5 \times$ $10^{9} / \mathrm{L}$, platelets $\geq 100 \times 10^{9} / \mathrm{l}$, and hemoglobin $\geq 9 \mathrm{~g} / \mathrm{dL}$ ), hepatic (total bilirubin $<1$ fold of the upper limit of normal value, aspartate aminotransaminase and alanine aminotransferase $<1.5$ fold of the upper limit of normal value, and it may be elevated to 3 fold of the upper limit of normal value in patients with known hepatic metastases), and renal (a calculated creatinine clearance rate of $<45$ $\mathrm{ml} / \mathrm{min}$ ) functions.

Patients with signs of malnourishment or $>10 \%$ weight loss in the past 6 weeks, or others serious concomitant disorders were excluded from the therapy. Patients were discontinued from the therapy in the case of evidence of progressive disease or unacceptable toxicity despite dose adjustment.

This study was conducted according to $\mathrm{ICH}$ Good Clinical Practice guidelines, including obtaining written informed consent from all patients.

\section{Study Medication}

Pemetrexed $500 \mathrm{mg} / \mathrm{m}^{2}$ was intravenously administered over 10-min on day 1 of a 21-day cycle, followed by cisplatin $75 \mathrm{mg} / \mathrm{m}^{2}$ administration intravenously over a 2-h infusion or carboplatin AUC 5 a 30-min infusion after pemetrexed administration. If a patient had been treated with cisplatin in last line chemotherapy, we gave the patient pemetrexed/carboplatin combination chemotherapy. Otherwise, we gave the patient pemetrexed/cisplatin combination chemotherapy. Dexamethasone $4 \mathrm{mg}$ was taken orally twice daily on the day before, the day of, and the day after each dose of pemetrexed. Folic acid supplementation $400 \mu \mathrm{g}$ was taken orally daily beginning 1 week prior to the first dose of pemetrexed and continued until 3 weeks after study therapy discontinuation. Vitamin B12 $1000 \mu \mathrm{g}$ was intramuscularly injected, starting 1 week prior to day 1 of cycle 1 and repeated every 9 weeks until study discontinuation.

If a patient experienced unacceptable toxicities, treatment was delayed for up to 42 days from day 1 of any cycle to allow recovering from toxicities. When Common Toxicity Criteria (CTC) grade 3/4 symptoms resolved, therapy was resumed at $75 \%$ of the previous dose. Any patient requiring $>42$ days recovery time or $>2$ reductions due to toxicity was to be withdrawn from the study. If patient required radiotherapy during the study, pemetrexed was discontinued until 2 weeks after the completion of radiotherapy.

\section{Assessments}

Baseline tumor measurements were taken no more than 2 weeks before treatment. At the end of the treatment period, the best tumor response rate was evaluated using the same imaging technique that was used at baseline and the Response Evaluation Criteria in Solid Tumors (RECIST) were recommended [23]. The progression free survival (PFS) was defined as the time from study entry to disease progression or death. The overall survival time (OS) was the time from study entry to death due to any cause. The safety measures including adverse events, physical examinations and clinical laboratory tests (hematology, blood chemistry, hepatic functions and renal functions) were completed before each cycle. Toxicities were graded using version 2.0 of the National Cancer Institute Common Toxicity Criteria [24].

\section{Statistical Methods}

We planned to have up to 53 qualified patients to be enrolled in a two stage sequential, non-comparative study with the possibility of stopping the study early for lack of efficacy. Nineteen qualified patients were enrolled in the first stage. If at least twelve patients achieved disease control, thirty-four additional patients were accrued. The significance level (i.e., the probability of rejecting the Ho 
when it is true) is $5 \%$. The power (i.e., the probability of rejecting Ho when the alternative hypothesis is true) is $80 \%$ [25-29].

The statistical analysis was performed using the Statistical Package for Social Science (SPSS) 17.0. Summary statistics were given for patient characteristics, treatment administration and all safety variables. Frequencies are reported as number and percentage. Efficacy analyses and safety analyses were conducted on all patients who received at least one dose of study drug. The objective response of chemotherapy was defined with an overall best response during treatment. PFS and OS time were analyzed by means of Kaplan-Meier method.

\section{Results}

Between December 2005 and May 2008, a total of 53 patients entered the study. The baseline patient characteristics were listed in Table 1. The median age was 52 years (range, 34-68 years), and there were 39 male and 14 female patients. Most patients had a good performance status, but thirteen patients had ECOG performance sta-

\section{Table 1: Demographic data for patients treated with} pemetrexed plus platinum $(n=53)$.

\begin{tabular}{ll}
\hline Patient criteria & $\mathbf{N}(\%)$ \\
\hline Patient number & 53 \\
Median age (range) & $52(34--68)$ \\
Sex & \\
Male & $39(73.6)$ \\
Female & $14(26.4)$ \\
Weight, kg: mean \pm SD & $69 \pm 10.1(40--96)$ \\
(range) & \\
Stage & $15(28.3)$ \\
IIIB & $38(71.7)$ \\
IV & \\
ECOG Performance status & $4(7.5)$ \\
0 & $36(67.9)$ \\
1 & $13(24.5)$ \\
2 & \\
Histology & $31(58.5)$ \\
Adenocarcinoma & $6(11.3)$ \\
Alveolar carcinoma & $14(26.4)$ \\
Squamous carcinoma & $1(1.9)$ \\
Large cell carcinoma & $1(1.9)$ \\
Mixed carcinoma & \\
No. chemotheraphy line & \\
Second line & $15(28.3)$ \\
Third line & $(7.5)$ \\
\hline & \\
Fourth lines & \\
\hline
\end{tabular}

tus 2. Thirty-eight patients had stage IV tumors. Thirtyseven patients had adenocarcinoma (including 6 alveolar carcinoma patients). Fourteen patients had squamouscell carcinoma. One patient had large cell carcinoma. One patient had mixed carcinoma. The median interval from the primary diagnosis to the beginning of the study treatment was 8.8 months. The follow-up period varied from 1 to 42 months (mean 11.3 months, median 10 months). Thirty-two patients received pemetrexed plus cisplatin chemotherapy, and twenty-one patients received pemetrexed combined with carboplatin therapy. Out of these 53 patients, 34 were treated in second line (64.2\%), 15 in third line (28.3\%), and 4 in fourth line (7.5\%). Every patient received at least one cycle of chemotherapy of pemtrexed with cisplatin/carboplatin. The total number of chemotheraphy cycles given was 189 , while the median number of cycles received was 3.0 (range 1-10). 12 patients $(22.6 \%)$ had dose modification at least in one cycle: The pemetrexed dose was reduced due to adverse events in 4 patients and was delayed (mostly due to adverse events) in 10 patients. At the end of the follow-up in May 2009, 2 patients were lost to follow-up after tumor recurrence, 6 patients had no disease progression, and 17 patients were still alive.

\section{Efficacy}

Of the 53 patients treated with pemetrexed plus platinum, no complete response (CR) were observed, whereas 7 patients achieved partial response (PR). The objective response rate $(\mathrm{ORR}=\mathrm{CR}+\mathrm{PR})$ was $13.2 \%$. In the remaining patients, $36(67.9 \%)$ achieved stable disease (SD), 10 (18.9\%) had progressive disease (PD). Thus, the disease control rate $(\mathrm{DCR}=\mathrm{CR}+\mathrm{PR}+\mathrm{SD})$ in this study was $81.1 \%$. Tumor response is summarized in Table 2. The median PFS time was 6.0 months [95\% confidence interval (CI): 4.6 to 7.4 ] and the median OS time was 10.0 months (95\% CI: 9.1 to 13.0). Kaplan-Meier plots for PFS and OS are displayed in Figure 1 and 2, respectively. The 1 -year survival rate was $40.9 \%$.

\section{Toxicity}

Toxicity was evaluated in all patients and in all cycles, and it was showed in Table 3. Forty-two patients $(79.2 \%$ of those treated) reported at least one adverse event during the study, 7 patients (13.2\%) and 5 patients (9.4\%) experienced grade 3 and grade 4 adverse events, respectively. The most common adverse events were leucopenia (49.1\% of treated patients), nausea/vomiting (49.1\% of treated patients), Neutropenia (37.7\% of treated patients), Thrombocytopenia $(32.1 \%$ of treated patients) and fatigue (18.9\% of treated patients). Gastrointestinal disorders (49.1\%) and blood system disorders $(49.1 \%)$ were the system organ classes with the highest incidence of adverse events related to treatment. 


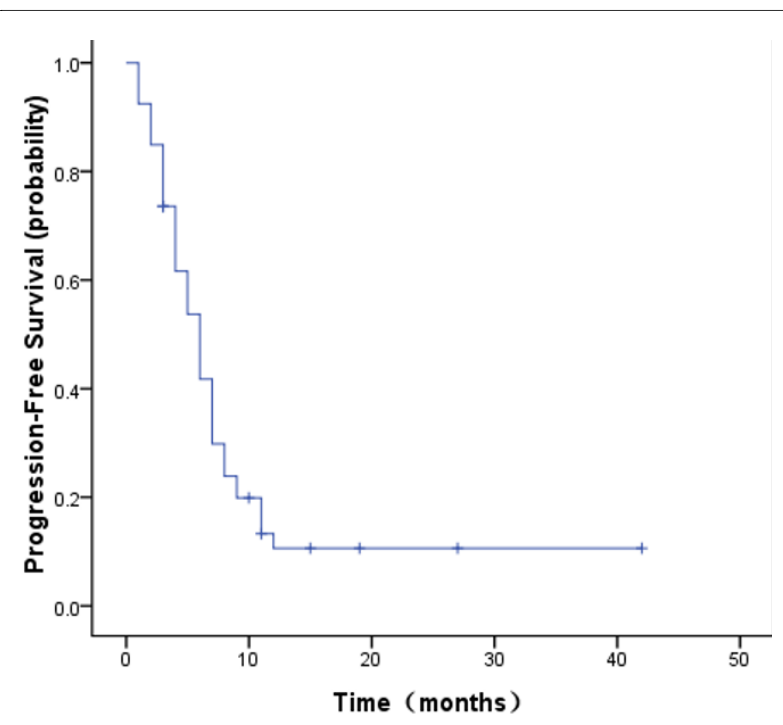

Figure 1 Kaplan--Meier curve of progression-free survival for patients treated with pemetrexed plus platinum $(n=53)$

The incidences of CTC grade $3 / 4$ adverse events were blood system disorders (16.9\%), gastrointestinal disorders (3.8\%), kidney function disorders (1.9\%) and rash (1.9\%). Grade 3 adverse events reported included leukopenia (3 patients), thrombocytopenia (2 patients), nausea/vomiting ( 1 patient), and rash (1 patient). Grade 4 adverse events included leukopenia (2 patients), thrombocytopenia ( 2 patients), diarrhea (1 patient) and Creatinine increase (1 patient).

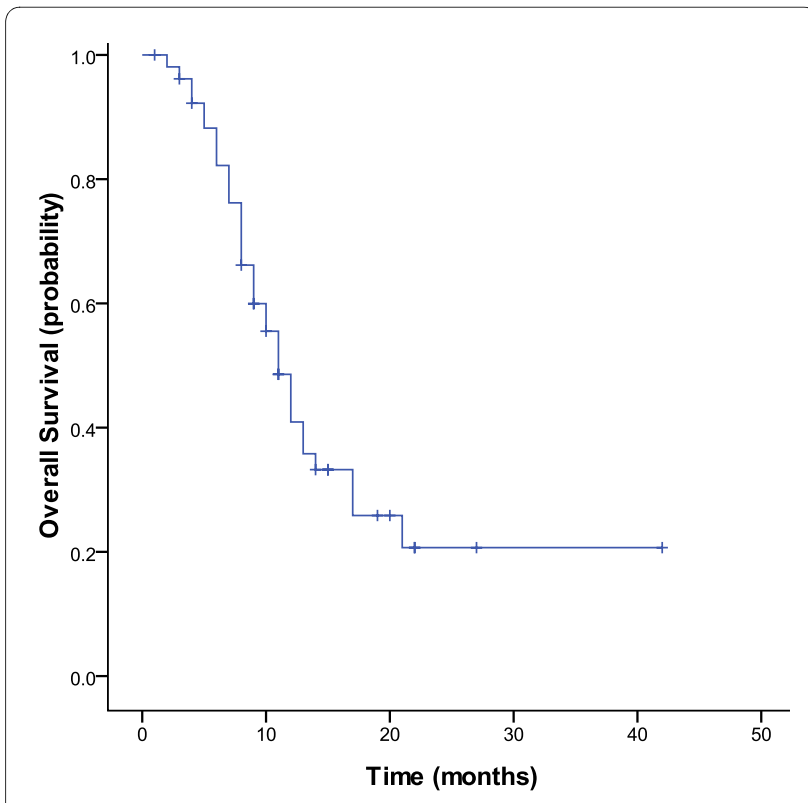

Figure 2 Kaplan--Meier curve of overall survival for patients treated with pemetrexed plus platinum $(n=53)$.
In the study endpoint, 34 patients (63.9\%) died due to disease progression: 1 patient (1.9\%) died within 30 days of treatment discontinuation, and 33 patients died after 30 days from treatment discontinuation.

\section{Discussion}

A multicenter, international, randomized phase III trial reported by Hanna et al compared single-agent pemetrexed with docetaxel in previously treated NSCLC patients. Until that trial, docetaxel was the only approved cytotoxic chemotherapy for second-line NSCLC treatment. Five hundred and seventy-one patients were randomized to pemetrexed $500 \mathrm{mg} / \mathrm{m}^{2}$ or docetaxel $75 \mathrm{mg} /$ $\mathrm{m}^{2}$ on day 1 of a 3-week cycle. Dexamethasone, folic acid and vitamin B12 were given every cycle. Overall response rates for pemetrexed and docetaxel were $9.1 \%$ and $8.8 \%$, respectively $(\mathrm{P}=0.105)$. The stable disease rate was $45.8 \%$ for pemetrexed and $46.8 \%$ for docetaxel. Both treatment groups exhibited similar median progression-free survival and 1-year survival rates of 2.9 months and 29.7\%, respectively. Median survival for pemetrexed and docetaxel was 8.3 and 7.9 months, respectively $(P=0.226)$. There was no difference in symptom improvement between the pemetrexed and docetaxel groups $(\mathrm{P}=$ $0.145)$. Hematologic adverse effects--grade $3 / 4$ neutropenia $(40.2 \%$ versus $5.3 \%$; $\mathrm{P}<0.001)$, febrile neutropenia (12.7\% versus $1.9 \%$; $\mathrm{P}<0.001)$, and neutropenic infections $(3.3 \%$ versus $0 \%$; $\mathrm{P}=0.004)$--were significantly greater in the patients who received docetaxel versus those who received pemetrexed. 125 elevation of ALT was the only adverse event occurring more often in the pemetrexed group $(\mathrm{P}=0.028)$. The results of the phase III study indicated pemetrexed is a viable option for secondline treatment in NSCLC, and provided an objective response and symptomatic benefit in conjunction with a favorable safety profile. Based on this trial, the U.S. FDA approved pemetrexed for second-line treatment of locally advanced or metastatic NSCLC [6].

In our study, 53 patients were enrolled. All patients had experienced platinum-based chemotherapy. Most of patients $(>70 \%)$ had good clinical conditions (ECOG PS 0 or 1). The patients treated with pemetrexed plus platinum were supplemented with dexamethasone, folic acid and vitamin B12. The addition of folic acid and vitamin B12 supplementation markedly reduced the toxicity profile of pemetrexed, as shown in a previous trial comparing pemetrexed administered with or without vitamins [30]. The median number of cycles received was 3 . No patient achieved CR. Seven of the 53 patients (13.2\%) showed PR. The ORR (13.2\%) is higher than that of single pemetrexed (8.8\%) reported by Hanna et al. The stable disease rate was $67.9 \%$ in this study, which was markedly higher than that of single pemetrexed (45.8\%) in Hanna's study. The 
Table 2: Response for patients treated with pemetrexed plus platinum $(n=53)$.

\begin{tabular}{lcc}
\hline Response & $\mathbf{N}(\%)$ & $\mathbf{9 5 \%} \mathbf{C l}$ (\%) \\
\hline CR & - & - \\
PR & $7(13.2)$ & 5.48 to 25.34 \\
SD & $36(67.9)$ & 56.68 to 80.08 \\
PD & $10(18.9)$ & 9.44 to 31.97 \\
\hline
\end{tabular}

$\mathrm{Cl}$, confidence interval; - , no data.

DCR for pemetrexed plus cisplatin/carboplatin in this study and single pemetrexed in Hanna's study were $81.1 \%$ and $54.6 \%$, respectively, which also have a significant difference. The median progression-free survival was 6.0 months, which was two times longer than that of single pemetrexed (2.9 months) in Hanna's study. The median OS time was 10.0 months, which was also longer than that of single pemetrexed ( 8.3 months). The 1-year survival rate was $40.9 \%$, which was higher than that of single pemetrexed (29.7\%) in Hanna's study. Compared with pemetrexed single agent chemotherapy, our study showed that locally advanced or metastatic NSCLC patients having experienced platinum-based chemotherapy might acquire a higher objective response rate, higher disease control rate, longer PFS, longer OS and higher 1year survival rate from pemetrexed combined with platinum chemotherapy. The main reason we achieved better results should be due to the addition of platinum chemotherapy drugs. Of course, to exclude the impact of race factor, we need further randomized controlled study.
In our study, the most frequent hematological toxicities were neutropenia and thrombocytopenia (any grade) and the most frequent nonhematological toxicities were nausea/vomiting, fatigue, pyrexia and rash (any grade). The incidence of grade 3/4 neutropenia and thrombocytopenia was $9.5 \%$ and $7.6 \%$, which was higher than that of pemetrexed single agent chemotherapy in Hanna's randomized phase III study (5.3\% and $1.9 \%$ ). The incidence of grade $3 / 4$ Anemia was 0 , which was $4.2 \%$ in that randomized phase III study. The nonhematological toxicities were similar to single pemetrexed observed in Hanna's study. Although the incidence of neutropenia and thrombocytopenia in pemetrexed plus cisplatin/carboplatin chemotherapy for previously treated locally advanced or metastatic NSCLC patients was slightly higher than pemetrexed single chemotherapy, the adverse events were tolerable. After treated, all patients acquired recovery from hematological toxicities. In this study, no patient died of chemotherapy.

Another study comparing pemetrexed with pemetrexed plus carboplatin in patients experiencing relapse after platinum-based chemotherapy showed that adding carboplatin to second-line pemetrexed treatment significantly increases ORR and PFS in patients with NSCLC after having received first-line platinum-based chemotherapy [31]. This conclusion is consistent with our results. However, the patients in the latter study did not receive a longer OS for pemetrexed combined with carboplatin chemotherapy compared with pemetrexed single agent chemotherapy, which may be associated with the application of different platinum. In our study, 21 patients (40\% of all patients enrolled) received pemetrexed/carboplatin chemotherapy, while the remaining 32

Table 3: Toxicity for patients treated with pemetrexed plus platinum ( $n=53)$.

\begin{tabular}{|c|c|c|c|c|c|}
\hline Adverse event & Any grade $\geq 1$ & Grade 1 & Grade 2 & Grade 3 & Grade 4 \\
\hline Leucopenia & $26(49.1)$ & 10 (18.9) & $11(20.8)$ & $3(5.7)$ & $2(3.8)$ \\
\hline Neutropenia & $20(37.7)$ & $6(11.3)$ & $9(17.0)$ & $3(5.7)$ & $2(3.8)$ \\
\hline $\begin{array}{l}\text { Thrombocytopeni } \\
\text { a }\end{array}$ & $17(32.1)$ & $11(20.8)$ & $2(3.8)$ & $2(3.8)$ & $2(3.8)$ \\
\hline Anemia & $8(15.1)$ & $4(7.5)$ & $4(7.5)$ & - & - \\
\hline ALT/AST & $3(5.7)$ & $3(5.7)$ & - & - & - \\
\hline Nausea/Vomiting & $26(49.1)$ & $16(30.2)$ & $9(17.0)$ & $1(1.9)$ & - \\
\hline Diarrhea & $1(1.9)$ & - & - & - & $1(1.9)$ \\
\hline Creatinine & $1(1.9)$ & - & - & - & $1(1.9)$ \\
\hline Pyrexia & $5(9.4)$ & $4(7.5)$ & $1(1.9)$ & - & - \\
\hline Fatigue & $10(18.9)$ & 10 (18.9) & - & - & - \\
\hline Rash & $5(9.4)$ & $1(1.9)$ & $3(5.7)$ & $1(1.9)$ & - \\
\hline Inflammation & $3(5.7)$ & - & $3(5.7)$ & - & - \\
\hline
\end{tabular}

Data are number of patients with rates in brackets 
patients (60\% of all patients enrolled) received pemetrexed/cisplatin chemotherapy. All of the patients received pemetrexed/carboplatin chemotherapy in the latter study. In addition, racial differences may also be a factor. Our data came from the Chinese people, and their data came from non-Asians.

In short, the study showed, locally advanced or metastatic NSCLC patients previously treated with platinumbased chemotherapy could benefit from pemetrexed plus cisplatin/carboplatin chemotherapy with tolerable adverse events.

For patients with advanced or metastatic cancer, the quality of life is important. In our study, we found some patients' quality of life was obviously increased even though their tumor was stable or progressive after chemotherapy. Due to a minor flaw in the original study design, there are no available data on whether patients' qualities of life were increased or not.

Pemetrexed produces its cytotoxic effect by blocking intracellular thymidylate synthase, dihydrofolate reductase, and glycinamide ribonucleotide formyl transferase. A deeper knowledge of those target enzymes may be used in the future to identify patients' responses to pemetrexed [32]. The targeted compounds combined with chemotherapy regimens might represent the next step treatment of NSCLC and the characteristics of pemetrexed make it a candidate in therapies context.

This study reported clinical experience with pemetrexed plus platinum for previously treated patients with locally advanced or metastatic non-small cell lung cancer and further prospective randomized clinical trials will confirm whether pemetrexed combined with platinum is a valid option for pretreated locally advanced or metastatic NSCLC patients.

\section{Competing interests}

The authors declare that they have no competing interests.

\section{Authors' contributions}

All authors have contributed substantially to the study. GZZ contributed to the design of the study, to the recruitment of patients, to analysis of data, to writing of manuscript, and to the revision of the manuscript. SCJ contributed to the conception and design of the study, to the critical revision of the manuscript, and to financial support prior to publication. ZTM have given contributions in the recruitment of patients. All authors read and approved the final manuscript.

\section{Acknowledgements}

We wish to thank Li-Xin Xie for his guidance in the writing of this manuscript. We are also grateful to medical personnel of Department of Oncology Medicine and Department of Respiratory Medicine of Chinese PLA General Hospital, which treated the patients in this study.

\section{Author Details}

Department of Oncology Medicine, Chinese PLA General Hospital, 28\# Fuxing Road, Haidian District, Beijing, 100853, PR China

Received: 19 January 2010 Accepted: 27 April 2010

Published: 27 April 2010

\section{References}

1. Ho C, Davies AM, Lara PN Jr, Gandara DR: Second-line treatment for advanced-stage non-small celllung cancer: current and future options. clin lung cancer 2006, 7(Supple 4):S118-125.

2. Felip E, Rosell R, Pampaloni G: Pemetrexed as second-line therapy for advanced non-small-cell lung cancer (NSCLC). Ther Clin/ Risk Manag 2008, 4(3):579-585.

3. Russo FBA, Pampaloni G: Pemetrexeed single agent chemotherapy in previously treated patients with local advanced or metastatic nonsmall cell lung cancer. BMC Cancer 2008, 8:216-223.

4. Pfister DG, Johnson DH, Azzoli CG, Sause W, Smith TJ, Baker S Jr, Olak J, Stover D, Strawn JR, Turrisi AT, Somerfield MR: American society of clinical oncology treatment of unresectable non-small-cell lung cancer guideline: Update 2003. J Clin Oncol 2004, 22:330-353.

5. Marinis F, Grossib F: Clinical evidence for second- and third-line treatment options in advanced non-small cell lung cancer. Oncologist 2008, 13(suppl 1):14-20.

6. Hanna N, Shepherd FA, Fossella FV, Pereira JR, De Marinis F, von Pawel J, Gatzemeier U, Tsao TC, Pless M, Muller T, Lim HL, Desch C, Szondy K, Gervais R, Shaharyar, Manegold C, Paul S, Paoletti P, Einhorn L, Bunn PA Jr: Randomized phase III trial of pemetrexed versus docetaxel in patients with non-small-cell lung cancer previously treated with chemotherapy. J Clin Oncologist 2004, 22(9):1589-1597.

7. Rollins KD, Lindley C: Pemetrexed: a multitargeted antifolate. Clin Ther 2005, 27(9):1343-1382.

8. Cohen MH, Johnson JR, Wang YC, Sridhara R, Pazdur R: FDA drug approval summary: pemetrexed for injection (Alimta) for the treatment of non-small cell lung cancer. Oncologist 2005, 10:363-368.

9. Shepherd FA, Rodrigues Pereira J, Ciuleanu T, Tan EH, Hirsh V, Thongprasert S, Campos D, Maoleekoonpiroj S, Smylie M, Martins R, van Kooten M, Dediu M, Findlay B, Tu D, Johnston D, Bezjak A, Clark G, Santabárbara $P$, Seymour L: Erlotinib in previously reated non-small-cell lung cancer. NEngl J Med 2005, 353:123-132

10. Hanauske AR, Eismann U, Oberschmidt O, Pospisil H, Hoffmann S, Hanauske-Abel H, Ma D, Chen V, Paoletti P, Niyikiza C: In vitro chemosensitivity of freshly explanted tumor cells to pemetrexed is correlated with target gene expression. Invest new drug 2007, 25(5):417-423

11. Scagliotti GV, Kortsik C, Dark GG, Price A, Manegold C, Rosell R, O'Brien M, Peterson PM, Castellano D, Selvaggi G, Novello S, Blatter J, Kayitalire L, Crino L, Paz-Ares L: Pemetrexed combined with oxaliplatin or carboplatin as first-line treatment in advanced non-small cell lung cancer: a multicenter, randomized, phase II trial. Clin Cancer Res 2005, 11:690-696.

12. Seiwert TY, Connell PP, Mauer AM, Hoffman PC, George CM, Szeto L, Salgia R, Posther KE, Nguyen B, Haraf DJ, Vokes EE: A phase I study of pemetrexed, carboplatin, and concurrent radiotherapy in patients with locally advanced or metastatic non-small cell lung or esophageal cancer. Clin Cancer Res 2007, 3:515-522.

13. Kreuter M, Vansteenkiste J, Griesinger F, Hoffmann H, Dienemann H, De Leyn $\mathrm{P}$, Thomas M: Trial on refinement of early stage non-small cell lung cancer. Adjuvant chemotherapy with pemetrexed and cisplatin versus vinorelbine and cisplatin: the TREAT protocol. BMC Cancer 2007, 7:77.

14. Scagliotti GV, Parikh P, von Pawel J, Biesma B, Vansteenkiste J, Manegold C, Serwatowski P, Gatzemeier U, Digumarti R, Zukin M, Lee JS, Mellemgaard A, Park K, Patil S, Rolski J, Goksel T, de Marinis F, Simms L, Sugarman KP, Gandara D: Phase III study comparing cisplatin plus gemcitabine with cisplatin plus pemetrexed in chemotherapy-naive patients with advanced-stage NSCLC. J Clin Oncol 2008, 26:3543-3551.

15. Ricciardi S, Tomao S, de Marinis F: Pemetrexed as first-line therapy for non-squamous non-small cell lung cancer. Ther Clin Risk Manag 2009, 5:781-787.

16. Scagliotti G, Hanna N, Fossella F, Sugarman K, Blatter J, Peterson P, Simms $L$, Shepherd FA: The differential efficacy of pemetrexed according to NSCLC histology: a review of two phase III studies. Oncologist 2009, 14:253-263.

17. Rossi A, Ricciardi S, Maione P, de Marinis F, Gridelli C: Pemetrexed in the treatment of advanced non-squamous lung cancer. Lung Cancer 2009 66(2):141-149.

18. Stinchcombe TE, Socinski MA: Current treatments for advanced stage non-small cell lung cancer. Proc Am Thorac Soc 2009, 6(2):233-241. 
19. Stinchcombe TE, Socinski MA: Considerations for second-line therapy of non-small cell lung cancer. Oncologist 2008, 13(Suppl 1):28-36.

20. Obasaju CK, Ye Z, Wozniak AJ, Belani CP, Keohan ML, Ross HJ, Polikoff JA, Mintzer DM, Monberg MJ, Jänne PA: Single-arm, open label study of pemetrexed plus cisplatin in chemotherapy naïve patients with malignant pleural mesothelioma: outcomes of an expanded access program. Lung Cancer 2007, 55(2):187-194.

21. Shepherd FA, Dancey J, Arnold A, Neville A, Rusthoven J, Johnson RD, Fisher B, Eisenhauer E: Phase II study of pemetrexed disodium, a multitargeted antifolate, and cisplatin as first-line therapy in patients with advanced nonsmall cell lung carcinoma: a study of the National Cancer Institute of Canada Clinical Trials Group. Cancer 2001, 92(3):595-600.

22. Garin A, Manikhas A, Biakhov M, Chezhin M, Ivanchenko T, Krejcy K, Karaseva V, Tjulandin S: A phase II study of pemetrexed and carboplatin in patients with locally advanced or metastatic breast cancer. Breast Cancer Res Treat 2008, 110(2):309-315.

23. Therasse P, Arbuck SG, Eisenhauer EA, Wanders J, Kaplan RS, Rubinstein L, Verweij J, Van Glabbeke M, van Oosterom AT, Christian MC, Gwyther SG: New guidelines to evaluate the response to treatment in solid tumors. J Natl Cancer Inst 2000, 92(3):205-216.

24. Investigator's handbook: a manual for participants in clinical trials of investigational agents sponsored by the Division of Cancer Treatment National Cancer Institute [http://ctep.cancer.gov/ investigatorResources/investigators handbook.htm

25. Simon R: Optimal two-stage designs for phase II clinical trials. Controlled Clini Trials 1989, 10:1-10.

26. Stallard N, Cockey L: Two-stage designs for phase II cancer trials with ordinal responses. Contemp Clin Trials 2008, 29(6):896-904

27. Logan BR: Optimal two-stage randomized phase II clinical trials. Clin Trials 2005, 2(1):5-12.

28. Ye F, Shyr Y: Balanced two-stage designs for phase II clinical trials. Clin Trials 2007, 4(5):514-524

29. Manegold C, Gatzemeier U, von Pawel J, Pirker R, Malayeri R, Blatter J, Krejcy K: Front-line treatment of advanced non-small-cell lung cancer with MTA (LY23 pemetrexed disodium, ALIMTA) and cisplatin: a multicenter phase II trial. Ann Oncol 1514, 11(4):435-440.

30. Scagliotti GV, Shin DM, Kindler HL, Vasconcelles MJ, Keppler U, Manegold C, Burris H, Gatzemeier U, Blatter J, Symanowski JT, Rusthoven JJ: Phase II study of pemetrexed with and without folic acid and vitamin B12 as front-line therapy in malignant pleural mesothelioma. $J$ Clin Oncol 2003, 21(8):1556-1561.

31. Smit EF, Burgers SA, Biesma B, Smit HJ, Eppinga P, Dingemans AM, Joerger $M$, Schellens JH, Vincent A, van Zandwijk N, Groen HJ: Randomized phase II and pharmacogenetic study of pemetrexed compared with pemetrexed plus carboplatin in pretreated patients with advanced non-small-cell lung cancer. J Clin Oncol 2009, 27(12):2038-2045.

32. Monnerat C, Le Chevalier T: Review of the pemetrexed and gemcitabine combination in patients with advanced-stage non-small cell lung cancer. Ann Oncol 2006, 17(Suppl 5):86-90.

doi: 10.1186/1756-9966-29-38

Cite this article as: Zhang et al., Pemetrexed plus cisplatin/carboplatin in previously treated locally advanced or metastatic non-small cell lung cancer patients Journal of Experimental \& Clinical Cancer Research 2010, 29:38

Submit your next manuscript to BioMed Central and take full advantage of:

- Convenient online submission

- Thorough peer review

- No space constraints or color figure charges

- Immediate publication on acceptance

- Inclusion in PubMed, CAS, Scopus and Google Scholar

- Research which is freely available for redistribution

Submit your manuscript at www.biomedcentral.com/submit
C) Biomed Central 